\title{
Pre-Operative Enhanced Recovery After Surgery (ERAS) Protocol Compliance Towards Major Surgery Patients at Dr. Soetomo General Hospital, Surabaya
}

\author{
Ahmad Sabili Rifa'i', Vicky Sumarki Budipramana², Gadis Meinar Sari3 ${ }^{3 *}$ \\ ${ }^{1}$ Faculty of Medicine, Universitas Airlangga, Surabaya, Indonesia \\ ${ }^{2}$ Department of Surgery, Digestive Surgery Division, Faculty of Medicine, Universitas Airlangga - Dr. Soetomo General \\ Hospital, Surabaya, Indonesia \\ ${ }^{3}$ Department of Physiology, Faculty of Medicine, Universitas Airlangga, Surabaya, Indonesia
}

\section{A R T I C L E I N F O}

\section{Article history:}

Received 11 May 2020

Received in revised form 28 May

2020

Accepted 02 June 2020

Available online 30 June 2020

\section{Keywords:}

Enhanced Recovery After Surgery (ERAS),

Surgery,

Pre-operative management.

*) Corresponding author:

gadis-m-s@fk.unair.ac.id

\section{A B S T R A C T}

Introduction: The implementation of ERAS protocol can optimize patients after surgery, which in turn can reduce burdens both for patient and hospital. The purpose of this study is to describe the compliance and consistency of ERAS in the pre-operative period of surgery patients in Dr. Soetomo General Hospital Surabaya.

Methods: We conducted consecutive observation of major surgical patients for 4 weeks. The type of surgery observed was digestive, thoracic and cardiovascular, and gynecological surgery. The preoperative period will be calculated for compliance based on the ERAS international protocol. All data of compliance presented descriptively.s.

Results: A total of 36 major surgery patients of which $7(19,4 \%)$ were digestive surgeries, 14 $(38,9 \%)$ were thoracic and cardiovascular surgeries, and $15(41,7 \%)$ were gynecological surgeries. Overall compliance of the ERAS protocol in the pre-operative period of major surgery patients was $91 \%$. The compliance of ERAS protocol in the pre-operative period of digestive surgery patients was $80 \%$, in thoracic and cardiovascular surgery patients was $93,4 \%$ and gynecologic surgery patients was $84.3 \%$. Major surgery patients with $\geq 90 \%$ compliance was $25 \%$. Digestive surgery patients with $\geq 90 \%$ compliance was $0 \%$. Thoracic and cardiovascular surgery patients with $\geq 90 \%$ compliance was $64,3 \%$. Gynecologic surgery patients with $\geq 90 \%$ compliance was $0 \%$.

Conclusion: : Pre-operative elements of ERAS protocol in major surgery including digestive, thoracic and cardiovascular, and gynecologic surgery in Dr. Soetomo General Hospital, Surabaya needs to be improved.

\section{Introduction}

Surgery is one of the most widely performed medical procedures in the world. ${ }^{1}$ Major surgery can cause postoperative complications which can worsen the patient's condition and increase the patient's mortality rate. ${ }^{2}$ This event can add cost and energy burdens to clinicians and patients. ${ }^{3}$ This has a major impact especially in the era of universal healthcare, where costs, labor and time must be minimized as much as possible to reduce risks and deficits. ${ }^{4}$ An effective way to prevent this complication is by applying ERAS protocol (Enhanced Recovery After Surgery)

The ERAS protocol is a multi-modal peri-operative treatment pathway that aims to restore the physiological state of the body post-surgery as optimal as possible before surgery and reduce the impact of surgical stress by giving operative patient right amount of care before, at, and after surgery. ${ }^{5}$ Research in China suggest that higher adherence to ERAS protocol has benefits to major surgery patients. ${ }^{6}$

However, ERAS protocol still faces various obstacles. This is because the ERAS protocol changes the existing operating care doctrine. ${ }^{7,8}$ The ERAS protocol component of the pre-operative period is the earliest treatment action and can determine the effect of subsequent peri-operative care. Dr. Soetomo General Hospital has many clinical practices carried out, including surgery. This study aims to determine the description of the adherence and consistency of preoperative management based on ERAS protocol. We 
used pre-operative part of the surgery for evaluation was because pre-operative ERAS protocols can be carried out in any hospital without sophisticated equipment and invasive procedures unlike the intra-operative period which including minimally invasive surgery. ${ }^{9}$ Thus, we can compared Dr. Soetomo General Hospital with another hospital with higher technological capabilities. The surgical procedures included in the research are digestive surgery, thoracic cardiovascular surgery, and gynecology/oncology surgery because the only available pathway in those 4 types of surgery. ${ }^{10,11,12,13}$

\section{Methods}

This was a descriptive-observational research by taking data from surgical patients consecutively for 4 weeks from 18 May 2019 to 1 June 2019 and 9 June 2019 to 22 June 2019 conducted at Dr. Soetomo General Hospital. The inclusion criteria were elective, major surgery patients with age above 18 years old and with types of surgery that has ERAS guidelines (digestive, thoracic and cardiovascular, and gynecologic). The exclusion criteria were patient underwent emergency surgery and minor surgery. Total number of surgery patients observed was 36 patients. The ethical clearance had approval from the research ethical committee of Dr. Soetomo General Hospital (110/KEPK/IV/2019).

Data from surgery patients was obtained by reading through the sheets related to the application of ERAS in the patient's medical record while the patient had still monitored inward. Data including SOAP (Subjective, Objective, Assesment, Plan) sheets, intensive care/ high-care sheets, CIE (Consultation, Information, and Education) sheets, early adult nursing assessment sheets, medical assessment sheets, anesthesia and sedation sheets, medication sheets, laboratory examination sheets, and surgery sheets. Each patient then categorized into thirteen elements as seen from table 2 based on percentage of pre-operative care adherence to the patient $(>90 \%, 80-89 \%, 70-79 \%, 60-69 \%$, and $<60 \%$ respectively). ${ }^{14}$ All data analyzed by categorizing the data based on characteristics and compliances for different type of surgery, then comparing each types of surgery compliance of pre-operative ERAS protocol in Dr. Soetomo General Hospital. WPS Office 11 and SPSS 25 software was used for data collection, recording and calculation. Each type of surgeries compliance then compared with other hospital researches within the same type of surgery.

\section{Results}

\section{Characteristics of Major Surgery Patient}

Based on the data obtained from observations in table 1, the most number of patients in types of surgery category were gynecological/ surgery patients, $(n=15,41.7 \%)$ and the least number of patients were patients with digestive surgery $(n=7,19.4 \%)$. Majority of patients was female $(n=24,66.7 \%)$ with average age was $50 \pm$ 13,5 years.
Compliance with Pre-operative ERAS Protocol Elements in Major Surgery

In table 3, none of the patients had total adherence of less than $70 \%$ from thirteen elements listed in table 2. Almost all pre-operative ERAS elements had a percentage of $>90 \%$ except screening and treatment of anemia and pre-operative medical pre-habilitation.

Table 1. Types of surgery in surgery patients and characteristics

\begin{tabular}{lcccc}
\hline Categories & $\begin{array}{c}\text { Digestive } \\
\text { Surgery }\end{array}$ & $\begin{array}{c}\text { Thorax- } \\
\text { Cardiovascu- } \\
\text { larSurgery }\end{array}$ & $\begin{array}{c}\text { Gynecology/ } \\
\text { Oncology } \\
\text { Surgery }\end{array}$ & Total \\
\hline $\begin{array}{l}\text { Number of } \\
\text { Patient }\end{array}$ & 7 & 14 & 15 & 36 \\
\hline Sex & & & & \\
\hline Male & 3 & 8 & 0 & 12 \\
\hline Female & 4 & 6 & 15 & 24 \\
\hline Age & & & & \\
\hline$<40$ & 1 & 5 & 1 & 6 \\
\hline $41-50$ & 3 & 2 & 6 & 11 \\
\hline $51-60$ & 2 & 3 & 5 & 11 \\
\hline$>60$ & 1 & 4 & 3 & 8 \\
\hline PS-ASA & & & & \\
\hline 1 & 0 & 0 & 1 & 1 \\
\hline 2 & 7 & 3 & 12 & 22 \\
\hline 3 & 0 & 10 & 2 & 12 \\
\hline 4 & 0 & 1 & 0 & 1 \\
\hline
\end{tabular}

Table 2. Compliance with elements of the ERAS protocol preoperative period in major surgery patients

\begin{tabular}{lc}
\hline \multicolumn{1}{c}{$\begin{array}{c}\text { Pre-operative Elements of the } \\
\text { ERAS Protocol }\end{array}$} & $\begin{array}{c}\text { Elements } \\
\text { Compliance } \\
\text { Persentage } \\
\text { (\%) }\end{array}$ \\
\hline Pre-acceptance CIE provision & 100 \\
\hline Risk assessment & 100 \\
\hline Cessation of cigarettes & 91.7 \\
\hline Cessation of alcohol & 100 \\
\hline Pre-operative nutrition screening & 100 \\
\hline Anemia screening and treatment & 75 \\
\hline Physical pre-habilitation of the patient & 25 \\
\hline $\begin{array}{l}\text { Instructions for administration of liquid carbo- } \\
\text { hydrates and 2 hour pre-operative water fasting }\end{array}$ & 100 \\
\hline $\begin{array}{l}\text { Instructions for administration of solid car- } \\
\text { bohydrates and 6 hours pre-operative fasting }\end{array}$ & 100 \\
\hline $\begin{array}{l}\text { Instructions for pre-operative fluid and elec- } \\
\text { trolyte therapy }\end{array}$ & 97.2 \\
\hline Do not give anxiolytic drugs on pre-medication & 97,2 \\
\hline Prophylactic antibiotics & 100 \\
\hline $\begin{array}{l}\text { Reducing risk by replacing inhalation agents } \\
\text { and N2O with propofol and reducing opioids }\end{array}$ & 97.2 \\
\hline Total Compliance Persentage & 91 \\
\hline
\end{tabular}


Table 3. Compliance rate with elements of the ERAS protocol pre-operative period in major surgery patients

\begin{tabular}{ccc}
\hline $\begin{array}{c}\text { Pre-operative period } \\
\text { ERAS protocol } \\
\text { compliance rate }\end{array}$ & $\begin{array}{c}\text { Number } \\
\text { (n) }\end{array}$ & $\begin{array}{c}\text { Persentage } \\
(\%)\end{array}$ \\
\hline$\geq 90 \%$ & 9 & 25 \\
\hline $80-89 \%$ & 20 & 55.6 \\
\hline $70-79 \%$ & 7 & 19.4 \\
\hline $60-69 \%$ & 0 & 0 \\
\hline$<60 \%$ & 0 & 0 \\
\hline Total & 36 & 100 \\
\hline
\end{tabular}

Compliance with Pre-operative ERAS Protocol Elements in Thoracic and cardiovascular Surgery

Thoracic-cardiovascular surgery patient compliance at Dr. Soetomo General Hospital was higher than the two types of operations as seen in table 4 and 5 . In particular, prehabilitation elements in thoracic and cardiovascular surgery was more adhered than digestive surgery and gynecological surgery. Even so, this still needs improvement as prehabilitation was only done in half of the patients.

Compliance with Pre-operative ERAS Protocol Elements in Gynecologic Surgery

Total percentage of compliance in Dr Soetomo General Hospital ERAS preoperative protocol in gynecologic surgery on table 5 was $84.3 \%$. When compared with ERAS adherence to digestive surgery in table 4 and thoracic and cardiovascular surgery in table 5, gynecological surgery patient compliance at Dr. Soetomo General Hospital was between the two types of operations. In comparison to other research, compliance in Dr. Soetomo General Hospital still lacking.18,19 Unlike digestive surgery where bowel preparation was still done inconsistently, gynecological surgery particularly much newer to ERAS protocol implementation compared to digestive surgery. Thus, the change in bowel preparation is later than digestive surgery. 17

Table 5. Compliance rate with elements of the ERAS protocol pre-operative period digestive, thoracic and cardiovascular, and gynecologic surgery patients

\begin{tabular}{cccc}
\hline $\begin{array}{c}\text { Pre-operative } \\
\text { periodERAS } \\
\text { protocol } \\
\text { compliance } \\
\text { rate }\end{array}$ & $\begin{array}{c}\text { Persentage } \\
\text { in digestive } \\
\text { surgery(\%) }\end{array}$ & $\begin{array}{c}\text { Persentage in } \\
\text { thoracicand } \\
\text { cardiovascular } \\
\text { Surgery(\%) }\end{array}$ & $\begin{array}{c}\text { Persentagein } \\
\text { Gynecologic } \\
\text { Surgery(\%) }\end{array}$ \\
\hline$\geq 90 \%$ & 0 & 64,3 & 0 \\
\hline $80-89 \%$ & 71,4 & 28,6 & 74,3 \\
\hline $70-79 \%$ & 28,6 & 7,1 & 26,7 \\
\hline $60-69 \%$ & 0 & 0 & 0 \\
\hline$<60 \%$ & 0 & 0 & 0 \\
\hline Total & 100,0 & 100,0 & 100,0 \\
\hline
\end{tabular}

Table 4 Compliance with elements of the ERAS protocol pre-operative period in digestive, thoracic and cardiovascular, and gynecologic surgery patients

\begin{tabular}{|c|c|c|c|}
\hline Pre-operative Elements of the ERAS Protocol & $\begin{array}{c}\text { Elements } \\
\text { Compliance Persentagein } \\
\text { DigestiveSurgery }(\%)\end{array}$ & $\begin{array}{c}\text { Elements Compliance } \\
\text { Persentage in Thoracic } \\
\text { and cardiovascular } \\
\text { Surgery }(\%) \\
\end{array}$ & $\begin{array}{c}\text { Elements Compli- } \\
\text { ance Persentage } \\
\text { in Gynecologic } \\
\text { Surgery }(\%) \\
\end{array}$ \\
\hline Pre-acceptance CIE provision & 100 & 100 & 100 \\
\hline Risk assessment & 100 & 100 & 100 \\
\hline Cessation of cigarettes & 100 & 85,7 & 100 \\
\hline Cessation of alcohol & 100 & 100 & 100 \\
\hline Pre-operative nutrition screening & 100 & 100 & 100 \\
\hline Anemia screening and treatment & 71,4 & 78,6 & 73,3 \\
\hline Physical pre-habilitation of the patient & 14,3 & 57,1 & 0 \\
\hline $\begin{array}{l}\text { Instructions for administration of liquid carbohydrates and } 2 \\
\text { hour pre-operative water fasting }\end{array}$ & 100 & 100 & 100 \\
\hline $\begin{array}{l}\text { Instructions for administration of solid carbohydrates and } 6 \\
\text { hours pre-operative fasting }\end{array}$ & 100 & 100 & 100 \\
\hline Instructions for pre-operative fluid and electrolyte therapy & 100 & 92,9 & 100 \\
\hline $\begin{array}{l}\text { Do not give mechanical bowel preperation (for Digestive and } \\
\text { Gynecologic Surgery) }\end{array}$ & 42,9 & - & 6,7 \\
\hline Do not give anxiolytic drugs on pre-medication & 85,7 & 100 & 100 \\
\hline Opioid-sparing medication (for Digestive Surgery) & 0 & - & - \\
\hline Prophylactic antibiotics & 100 & 100 & 100 \\
\hline $\begin{array}{l}\text { Reducing risk by replacing inhalation agents and } \mathrm{N} 2 \mathrm{O} \text { with } \\
\text { propofol and reducing opioids }\end{array}$ & 85,7 & 100 & 100 \\
\hline Total Compliance Persentage & 80 & 93,4 & 84,3 \\
\hline
\end{tabular}




\section{Discussion}

ERAS protocol is done to reduce post-operative stress and complications. There are three parts of ERAS protocol which consists of pre-operative, intra-operative, and post-operative elements. First, elements of pre-operative ERAS protocol include education, risk assessment and reduction, fasting and nutrition enhancement, and preoperative medication including PONV (Post-Operative Nausea and Vomiting). Elements of intra-operative ERAS protocol consists of standard anesthetic protocol, intraoperative fluid therapy, surgical techniques, and hypothermia reduction. Finally, postoperative therapy including thromboprophylaxis, postoperative nutrition and fluid therapy, drain management, and early mobilization. Other criteria for peri-operative managements are not comprehensive like ERAS, for example there is only one criterion focusing on pre-operative fasting for long hours. ERAS criteria are based on comprehensive peri-operative treatment. Compared to old criteria for fasting, in ERAS, patient must be given nutrition before fasting and long hours of fasting are reduced. ${ }^{10,11,12,13,20}$

When compared among digestive surgery, thoracic and cardiovascular surgery, and gynecological surgery in table 2 and 4 , the total percentage of overall major surgery patients compliance was higher than digestive and gynecological operations combination and slightly lower than thoracic and cardiovascular operations. The least complied type of surgery in ERAS protocol was digestive surgery. This is because in digestive surgery, opioid sparing medication had not been used at all because the doctors were still inconsistent in adherence towards ERAS protocol. ${ }^{12}$

The pre-operative ERAS protocol that had been done the least were screening and treatment of anemia and preoperative medical pre-habilitation which contribute to decrease in compliance persentage. Screening of anemia had been done in all patients, but treatment in patients with anemia generally uses blood transfusions which can increase the risk of complications. ${ }^{21}$ Medical prehabilitation in all patients was not performed because the management system of Dr. Soetomo General Hospital is still inadequate to accommodate all major surgery patients. Medical pre-habilitation compliance was better in thoracic and cardiovascular surgery because more medical evidence supports pre-habilitation in this type of surgery compared to other operations. ${ }^{22}$ The lack part in compliance could be improved with better medical management and education to ERAS adherence.

This study has limitation in only focused on pre-operative elements, while ERAS is multimodal and interlinked between pre-operative, intra-operative, and post-operative to bring optimal result to patients. 12 The difficulties in Dr. Soetomo General Hospital to implement ERAS are lack of medical personnel knowledge and medical management system.

\section{Conflict of Interest}

The author stated there is no conflict of interest

\section{References}

1. Weiser, T., Regenbogen, S., Thompson, K., Haynes, A., Lipsitz, S., Berry, W. and Gawande, A. (2008). An estimation of the global volume of surgery: a modelling strategy based on available data. The Lancet, 372(9633), pp.139-144.

2. The International Surgical Outcomes Study group. Global patient outcomes after elective surgery: prospective cohort study in 27 low-, middle- and high-income countries. British Journal of Anaesthesia. 2016;117(5):601-609

3. Scott, M., Baldini, G., Fearon, K., Feldheiser, A., Feldman, L., Gan, T., Ljungqvist, O., Lobo, D., Rockall, T., Schricker, T. dan Carli, F. Enhanced Recovery After Surgery (ERAS) for gastrointestinal surgery, part 1: pathophysiological considerations. Acta Anaesthesiologica Scandinavica. 2015;59(10):1212-1231

4. Rarasati DH. Dampak kenaikan tarif BPJS Kesehatan Terhadap Pelayanan Kesehatan di Kota Malang. Jurnal Politik Muda. 2017;6(1):34-40.

5. Kehlet, H. Enhanced Recovery After Surgery (ERAS): good for now, but what about the future? Canadian Journal of Anesthesia/ Journal canadien d'anesthésie. 2014;62(2):99-104.

6. Li, L., Jin, J., Min, S., Liu, D. and Liu, L. Compliance with the enhanced recovery after surgery protocol and prognosis after colorectal cancer surgery: A prospective cohort study. Oncotarget. 2014;8(32).

7. Abeles, A., Kwasnicki, R. M., dan Darzi, A. Enhanced recovery after surgery: Current research insights and future direction. World Journal of Gastrointestinal Surgery. 2017;9(2), 37-45.

8. Melnyk, M., Casey, R., Black, P. and Koupparis, A. Enhanced recovery after surgery (ERAS) protocols: Time to change practice? Canadian Urological Association Journal, 2011:342348

9. Scott, M., Baldini, G., Fearon, K., Feldheiser, A., Feldman, L., Gan, T., Ljungqvist, O., Lobo, D., Rockall, T., Schricker, T. dan Carli, F. (2015). Enhanced Recovery After Surgery (ERAS) for gastrointestinal surgery, part 1: pathophysiological considerations. Acta Anaesthesiologica Scandinavica, 59(10), pp.1212-1231.

10. Batchelor, T., Rasburn, N., Abdelnour-Berchtold, E., Brunelli, A., Cerfolio, R., Gonzalez, M., Ljungqvist, O., Petersen, R., Popescu, W., Slinger, P. and Naidu, B. Guidelines for enhanced recovery after lung surgery: recommendations of the Enhanced Recovery After Surgery (ERAS ${ }^{\circledR}$ ) Society and the European Society of Thoracic Surgeons (ESTS). European Journal of Cardio-Thoracic Surgery. 2018;55(1):91-115.

11. Engelman, D., Ben Ali, W., Williams, J., Perrault, L., Reddy, V., Arora, R., Roselli, E., Khoynezhad, A., Gerdisch, M., Levy, J., Lobdell, K., Fletcher, N., Kirsch, M., Nelson, G., Engelman, R., Gregory, A. and Boyle, E. Guidelines for Perioperative Care in Cardiac Surgery. JAMA Surgery. 2019;154(8):755.

12. Gustafsson, U., Scott, M., Hubner, M., Nygren, J., Demartines, N., Francis, N., Rockall, T., Young-Fadok, T., Hill, A., Soop, M., de Boer, H., Urman, R., Chang, G., Fichera, A., Kessler, H., Grass, F., Whang, E., Fawcett, W., Carli, F., Lobo, D., Rollins, K., Balfour, A., Baldini, G., Riedel, B. and Ljungqvist, O. Guidelines for Perioperative Care in Elective Colorectal Surgery: Enhanced Recovery After Surgery (ERAS $®)$ Society Recommendations: 2018. World Journal of Surgery. 2018;43(3):659-695.

13. Nelson, G., Bakkum-Gamez, J., Kalogera, E., Glaser, G., Altman, A., Meyer, L., Taylor, J., Iniesta, M., Lasala, J., Mena, G., Scott, M., Gillis, C., Elias, K., Wijk, L., Huang, J., Nygren, J., Ljungqvist, O., Ramirez, P. and Dowdy, S. Guidelines for perioperative care in gynecologic/oncology: Enhanced Recovery After Surgery (ERAS) Society recommendations - 2019 update. International Journal of Gynecologic Cancer. 2019;29(4):651668.

14. Härma, E., Seire, I., Laas, A. dan Kütner, S. Adherence to the enhanced recovery after surgery (ERAS) protocol and outcomes after colorectal cancer surgery in North Estonia Medical Centre. Clinical Nutrition ESPEN. 2017;19:99.

15. Gustafsson, U., Hausel, J., Thorell, A., Ljungqvist, O., Soop, M. and Nygren, J., 2011. Adherence to the Enhanced Recovery After Surgery Protocol and Outcomes After Colorectal Cancer Surgery. Archives of Surgery, 146(5), p.571.

16. Ramírez, J., Blasco, J., Roig, J., Maeso-Martínez, S., Casal, J., Esteban, F. and Lic, D. (2011). Enhanced recovery in colorectal surgery: a multicentre study. BMC Surgery, 11(1).

17. Melnyk M, Casey RG, Black P, Koupparis AJ. Enhanced recovery after surgery (ERAS) protocols: Time to change practice? Canadian Urological Association Journal $=$ Journal de L'association des Urologues du Canada. 2011 Oct;5(5):342-348. DOI: $10.5489 /$ cuaj. 11002 . 
18. Bisch, S., Wells, T., Gramlich, L., Faris, P., Wang, X., Tran, D., Thanh, N., Glaze, S., Chu, P., Ghatage, P., Nation, J., Capstick, V., Steed, H., Sabourin, J. and Nelson, G. Enhanced Recovery After Surgery (ERAS) in gynecologic oncology: System-wide implementation and audit leads to improved value and patient outcomes. Gynecologic Oncology. 2018;151(1):117-123.

19. Wijk, L., Udumyan, R., Pache, B., Altman, A., Williams, L., Elias, K., McGee, J., Wells, T., Gramlich, L., Holcomb, K., Achtari, C., Ljungqvist, O., Dowdy, S. and Nelson, G. International validation of Enhanced Recovery After Surgery Society guidelines on enhanced recovery for gynecologic surgery. American Journal of Obstetrics and Gynecology. 2019;221(3):237.e1-237.e11.

20. Feldheiser, A., Aziz, O., Baldini, G., Cox, B., Fearon, K., Feldman, L., Gan, T., Kennedy, R., Ljungqvist, O., Lobo, D.,
Miller, T., Radtke, F., Ruiz Garces, T., Schricker, T., Scott, M., Thacker, J., Ytrebø, L. dan Carli, F. Enhanced Recovery After Surgery (ERAS) for gastrointestinal surgery, part 2: consensus statement for anaesthesia practice. Acta Anaesthesiologica Scandinavica, 2015;60(3):289-334.

21. Roulin, D., Muradbegovic, M., Addor, V., Blanc, C., Demartines, N. and Hübner, M. Enhanced Recovery after Elective Colorectal Surgery - Reasons for Non-Compliance with the Protocol. Digestive Surgery. 2016;34(3):220-226.

22. Sanchez-Lorente, D., Navarro-Ripoll, R., Guzman, R., Moises, J., Gimeno, E., Boada, M. and Molins, L. (2018). Prehabilitation in thoracic surgery. Journal of Thoracic Disease, 10(S22), pp.S2593-S2600. 